\title{
The use of Bimetallics to Control the Selectivity for the Upgrading of Lignin-Derived Oxygenates: Reaction of Anisole on Pt and PtZn Catalysts
}

\author{
Daming Shi, Lisandra Arroyo-Ramírez and John M. Vohs* \\ Department of Chemical \& Biomolecular Engineering, \\ University of Pennsylvania, Philadelphia, PA 19104-6363 (USA), \\ e-mail: vohs@ seas.upenn.edu, Phone: 1-215-898-6318
}

\begin{abstract}
The adsorption and reaction of anisole on Pt and PtZn catalysts was investigated using both model single crystal and high surface area supported metal catalysts. Temperature programmed desorption (TPD) and high resolution electron energy loss spectroscopy (HREELS) studies of the interaction of anisole with $\operatorname{Pt}(111)$ demonstrated that there is a strong interaction between the phenyl ring of anisole and the surface, resulting in $\mathrm{C}-\mathrm{O}$ and $\mathrm{C}-\mathrm{H}$ bond scission at relatively low temperatures. In contrast, anisole was observed to bond to a Zn-modified Pt(111) surface primarily via the oxygen at $\mathrm{Zn}$ sites or possibly adjacent Pt sites, with the phenyl ring tilted away from the surface. Such bonding configuration facilitated selective C-O bond cleavage producing phenyl groups and methoxide groups with the latter being bonded to the $\mathrm{Zn}$ sites. These results suggested that PtZn may be an effective catalyst for hydrodeoxygenation (HDO) of ligninderived aromatic oxygenates with low activity for ring hydrogenation. This hypothesis was then tested and verified by investigating the reaction of anisole and $\mathrm{H}_{2}$ over high surface area carbon-supported $\mathrm{Pt}$ and PtZn catalysts.
\end{abstract}

Keywords: anisole, lignin, hydrodeoxygenation (HDO), TPD, HREELS, bimetallic 


\section{Introduction}

Lignocellulosic biomass is emerging as an attractive, sustainable carbon feedstock for the production of fuels and chemicals [1-3]. While in recent years much effort has been focused on catalytic processing of the cellulosic fraction of biomass for this purpose [4-6], the lignin fraction is also a useful resource and provides a feedstock for the production of high-value aromatic compounds [2,7]. The refractory nature of lignin, however, makes its conversion to useful products more challenging than that of cellulose. Depolymerization of lignin is generally achieved via fast pyrolysis which produces a complex liquid mixture containing a range of substituted aromatics [8]. This bio-oil is highly oxygenated and subsequent hydrodeoxygenation (HDO) is usually required.

Conventional metal-sulfide based hydrotreating catalysts (e.g. sulfided CoMo) have been suggested for use in the upgrading and deoxygenation of lignin-derived aromatic oxygenates; unfortunately, they tend to produce less desirable ring saturation products and also rapidly deactivate due to coking [9-12]. Some success has been obtained using group 10 metal catalysts (i.e. $\mathrm{Ni}, \mathrm{Pd}, \mathrm{Pt}$ ), but they also promote hydrogenation of the aromatic rings [13,14]. Alloying a group 10 metal with a second more oxyphilic metal (e.g. Fe, Sn, Zn) [15-18], however, has emerged as a promising strategy for producing HDO catalysts that exhibit high selectivity for the production of aromatic hydrocarbons from lignin-derived oxygenates. Multiple studies have shown that alloying Pt or Pd with Sn or Fe weakens the interaction of the aromatic ring with the metal surface, and it has been proposed that this may affect the ring hydrogenation activity by altering the bonding configuration of aromatic oxygenates from one where the ring is lying flat on the surface to one where adsorption occurs primarily via the oxygen functionality [1921].

Recently our group has undertaken a series of mechanistic studies of the adsorption and reaction of benzaldehyde and other small aldehydes on Pt-Zn model catalysts consisting of a $\mathrm{Pt}(111)$ surface decorated with $\mathrm{Zn}$ adatoms [22-24]. Our studies of benzaldehyde on these catalysts provide direct evidence that alloying does indeed alter the bonding configuration of the phenyl ring with the ring tilting away from the surface upon $\mathrm{Zn}$ addition. Furthermore, these previous studies show that aldehydes bond to the $\mathrm{Zn} / \mathrm{Pt}(111)$ surface via the carbonyl in an $\eta_{2}$-configuration in which the oxygen in the carbonyl is bonded to a $\mathrm{Zn}$ site and the carbon is bonded to an adjacent Pt site. This bonding configuration results in a weakening of the $\mathrm{C}=\mathrm{O}$ bond which helps facilitate its cleavage.

In the work described here we have extended our previous studies of the reactivity of $\mathrm{Zn}$-modified Pt surfaces to include the adsorption and reaction of anisole $\left(\mathrm{CH}_{3} \mathrm{OC}_{6} \mathrm{H}_{5}\right)$. This molecule was chosen as a model aromatic compound that contains a C-O-C linkage which is commonly found in lignin-derived oxygenates [25-27]. Temperature-programmed desorption (TPD) and high-resolution electron energy loss spectroscopy (HREELS) were used to characterize the pathways and intermediates involved in the 
reaction of anisole on both $\mathrm{Pt}(111)$ and $\mathrm{Zn} / \mathrm{Pt}(111)$ surfaces. Based on the results for the model catalysts we have predicted trends in selectivity for the reaction of anisole on high surface area supported Pt and PtZn catalysts. These predictions were then tested by measuring product selectivity for the reaction of anisole over $\mathrm{Pt} / \mathrm{C}$ and $\mathrm{PtZn} / \mathrm{C}$ catalysts under typical $\mathrm{HDO}$ reaction conditions. The results from the model and high surface area catalysts together provide useful insight into the active sites in bimetallic HDO catalysts as well as how alloying can be used to limit activity for ring hydrogenation.

\section{Experimental}

The model catalyst studies in this work were conducted in an ultra-high vacuum (UHV) apparatus described in detail in previous publications [22, 28, 29]. The system had a background pressure operated at $2 \times 10^{-10}$ torr and was equipped with a quadruple mass spectrometer (SRS RGA200), an ion sputter gun (PHI electronics) and an HREEL spectrometer (LK Technologies). A Pt(111) single crystal substrate which was $10 \mathrm{~mm}$ in diameter and oriented to within $\pm 0.5^{\circ}$ was spot-welded to two tantalum wires that were connected to the UHV sample manipulator. The Pt(111) surface was cleaned by repeated cycles of 2 $\mathrm{kV} \mathrm{Ar}{ }^{+}$ion bombardment at $600 \mathrm{~K}$ for $40 \mathrm{~min}$, annealing at $1200 \mathrm{~K}$ under $2 \times 10^{-8}$ torr $\mathrm{O}_{2}$ for $15 \mathrm{~min}$, and annealing at $1200 \mathrm{~K}$ in vacuum for $5 \mathrm{~min}$. The sample was heated resistively and cooled to $110 \mathrm{~K}$ by conduction from a liquid $\mathrm{N}_{2}$ reservoir.

$\mathrm{Zn}$ deposition on $\mathrm{Pt}(111)$ was obtained by exposing the Pt surface to a beam of $\mathrm{Zn}$ atoms produced from an effusive source consisting of a coil of $\mathrm{Zn}$ wire (Alfa Aesa, 99.99\%) around a resistively heated tungsten filament. A quartz crystal microbalance (QCM) was used to monitor the $\mathrm{Zn}$ flux from the source and the total amount of $\mathrm{Zn}$ deposited was further quantified by measuring the area of the high-temperature $\mathrm{Zn}$ desorption feature in the TPD spectra [22, 30]. Detailed characterization of the structure of $\mathrm{Zn}$ modified Pt(111) surfaces has been reported previously [30]. In that study it was shown that for initial submonolayer amounts of $\mathrm{Zn}$ deposited with $\mathrm{Pt}(111)$ sample held at or below room temperature, the $\mathrm{Zn}$ diffuses into the surface upon annealing between 600 and $700 \mathrm{~K}$ with the equilibrium structure being one where the $\mathrm{Zn}$ atoms reside in the second and third layer below the surface. For this structure there are no $\mathrm{Zn}$ sites present on the $\mathrm{Pt}(111)$ surface. Since for this study we wanted to investigate how $\mathrm{Zn}$ affects reactivity via electronic interactions and its potential role as an active site for HDO, we chose to investigate $\mathrm{Pt}(111)$ surfaces that were decorated with $\mathrm{Zn}$ adatoms that were formed by $\mathrm{Zn}$ deposition with the $\operatorname{Pt}(111)$ sample below room temperature. Our previous studies have shown that $\mathrm{Zn}$ adatoms influence the electronic property of nearby surface Pt atoms in a manner similar to that in the bulk alloy [22].

For the UHV studies the anisole reactant (Sigma Aldrich, 99.7\%) was contained in a glass vial attached to a stainless steel manifold that was connected to the main UHV apparatus via a variable leak valve. A saturation exposure of anisole $(0.6 \mathrm{~L})$ was used in both the TPD and HREEL experiments. A 
heating rate of $3 \mathrm{~K} / \mathrm{s}$ was used in the TPD experiments and the HREEL spectra were collected using a 4 $\mathrm{eV}$ electron beam oriented at $60^{\circ}$ with respect to the surface normal. The full width at half-maximum of the elastic peak obtained from the clean surface was typically $40 \mathrm{~cm}^{-1}$. HREEL spectra were collected as a function of sample temperature. For temperatures greater than the dosing temperature the sample was heated at $3 \mathrm{~K} / \mathrm{s}$ to the indicated temperature and then rapidly quenched to low temperature at which point the spectrum was collected.

Micro flow reactor studies were also carried out to determine the reactivity of carbon supported Pt and PtZn catalysts for the HDO of anisole and to provide comparison data to the model catalyst studies. $\mathrm{Pt} / \mathrm{C}$ catalysts with $10 \mathrm{wt} \% \mathrm{Pt}$ were prepared by impregnation of carbon black (Vulcan XC-72R) with a water/ethanol (4:1) solution of tetraammineplatinum (II) nitrate $\left(\mathrm{Pt}\left(\mathrm{NH}_{3}\right)_{4}\left(\mathrm{NO}_{3}\right)_{2}, 99.99 \%\right.$, Alfa Aesar). The $10 \mathrm{wt} \% \mathrm{PtZn} / \mathrm{C}$ samples were prepared by co-impregnation with water/ethanol (4:1) solution of $\mathrm{Pt}\left(\mathrm{NH}_{3}\right)_{4}\left(\mathrm{NO}_{3}\right)_{2}$ and $\mathrm{Zn}\left(\mathrm{NO}_{3}\right)_{2} \bullet 6 \mathrm{H}_{2} \mathrm{O}$. Prior to reaction studies the catalysts were reduced in flowing $5 \%$ $\mathrm{H}_{2} / \mathrm{He}$ to $673 \mathrm{~K}$ with a heating ramp of $2 \mathrm{~K} / \mathrm{min}$, then to $773 \mathrm{~K}$ with heating ramp of $1 \mathrm{~K} / \mathrm{min}$ at which point it was held for $2 \mathrm{~h}$. PtZn catalysts were prepared with Pt:Zn molar ratios of 1:1 (PtZn/C) and 1:3 $\left(\mathrm{PtZn}_{3} / \mathrm{C}\right)$. Both the $\mathrm{PtZn} / \mathrm{C}$ and $\mathrm{PtZn}_{3} / \mathrm{C}$ catalysts had a total metals loading of $10 \mathrm{wt} \%$.

A high-pressure flow reactor that was similar to that described by Luo et al. [31] was used in the reactor studies. The reactor consisted of a $20 \mathrm{~cm}$ long, stainless-steel tube (4.6-mm ID) that was heated in a tube furnace. A 1 wt \% liquid solution of anisole (Sigma Aldrich, 99.7\%) dissolved in $n$-heptane (Sigma Aldrich, 99\%) was introduced into the reactor by an HPLC pump (Series III, Lab Alliance). The pump was also used to monitor the total pressure which was controlled by a back pressure regulator (KPB series, Swagelok) that was located downstream from the reactor. The pressure was fixed at 27.5 bar for all the experiments performed in this study. Hydrogen (Airgas, UHP grade) contained in a regulated, highpressure cylinder was delivered to the reactor through $2.44 \mathrm{~m}$ of capillary tubing $(50.8 \mu \mathrm{m}$ ID, Valco Instrument, Inc.). The $\mathrm{H}_{2}$ flow rate was a function of the cylinder outlet pressure and the pressure drop across the capillary tube. For a typical experiment, the liquid flow rate was set as $0.1 \mathrm{ml} / \mathrm{min}$, while the $\mathrm{H}_{2}$ flow rate was kept constant at $5 \mathrm{ml} / \mathrm{min}$ (STP).

For each catalyst test, $0.05 \mathrm{~g}$ of the catalyst was packed into the middle portion of the reactor and held in place by glass wool. Prior to rate measurements, each catalyst was pretreated by heating in 27.5 bar of flowing $\mathrm{H}_{2}$ at $573 \mathrm{~K}$ for $30 \mathrm{~min}$. Fresh samples were used for each experiment at a specified reaction condition. The liquid phase reaction products were collected at room temperature and a GC-MS (QP5000, Shimadzu) was used for identification and quantification of the produces. Product selectivity was quantified using solutions with known concentrations as standards. The reactivity data presented here were obtained $60 \mathrm{~min}$ after starting the reaction in order to allow steady state to be obtained. 


\section{Results and Discussion}

\subsection{Reaction of anisole on Pt(111)}

The initial studies of the adsorption and reaction of anisole were performed for the $\mathrm{Zn}$-free $\operatorname{Pt}(111)$ surface. TPD data collected as a function of coverage were used to determine the dosage required to saturate the surface with anisole, as determined by the appearance of a molecular anisole peak at $185 \mathrm{~K}$ corresponding to desorption of adsorbed multilayers. Based on these results, a $0.6 \mathrm{~L}$ anisole dose, which gives a coverage slightly more than one monolayer, was chosen for the more detailed TPD studies.

Fig.1 displays a complete set of TPD data obtained from the $\mathrm{Zn}$-free $\mathrm{Pt}(111)$ surface for the $0.6 \mathrm{~L}$ anisole dose. The two low-temperature anisole desorption peaks at 185 and $215 \mathrm{~K}$ correspond to physisorbed multilayers and chemisorbed anisole, respectively. The only reaction products detected for this surface were $\mathrm{H}_{2}$ and $\mathrm{CO}$. Hydrogen was produced in two distinct peaks centered at 350 and $480 \mathrm{~K}$, and a much broader feature that spanned from $530 \mathrm{~K}$ to $750 \mathrm{~K}$. The $\mathrm{H}_{2}$ peak at $350 \mathrm{~K}$ is at the same temperature as that reported for recombinative desorption of $\mathrm{H}$ atoms on $\mathrm{Pt}(111)$ [32] and therefore indicates that some $\mathrm{C}-\mathrm{H}$ bond scission in adsorbed anisole has already occurred by this temperature. $\mathrm{CO}$ was primarily produced in two peaks centered at 420 and $480 \mathrm{~K}$, with a smaller peak present at $530 \mathrm{~K}$. From the TPD data alone it is not possible to definitively assign these peaks as desorption or reaction limited, although the fact that both $\mathrm{CO}$ and $\mathrm{H}_{2}$ are produced at $480 \mathrm{~K}$ suggests that the $\mathrm{CO}$ at this temperature is reaction limited.

HREELS was used to provide insight into the identity of adsorbed intermediates formed from anisole on the $\operatorname{Pt}(111)$ surface. HREEL spectra as function of temperature for $\operatorname{Pt}(111)$ dosed with $0.6 \mathrm{~L}$ of anisole at $115 \mathrm{~K}$ are displayed in Fig. 2. As noted above, spectra corresponding to higher temperatures were obtained by briefly heating the sample to the indicated temperature and then letting it cool back to $115 \mathrm{~K}$, at which point the spectrum was collected. As would be expected, the spectrum obtained at $115 \mathrm{~K}$ contains peaks that are characteristic of molecular anisole and can be assigned via comparison to the corresponding IR and Raman spectra [33-35]. Individual peak assignments are given in Table 1.

Heating to $200 \mathrm{~K}$ to desorb physisorbed anisole caused only minor changes in the HREEL spectrum including an increase in the intensity of the out-of-plane $\gamma(\mathrm{C}-\mathrm{H})_{\text {ring }}$ peak at $820 \mathrm{~cm}^{-1}$, diminution in the intensity of the in-plane $\delta(\mathrm{C}-\mathrm{H})_{\text {ring }}$ peak at $1010 \mathrm{~cm}^{-1}$, and disappearance of the peak at $1250 \mathrm{~cm}^{-1}$ which is likely due to both $v(\mathrm{C}-\mathrm{OMe})$ and in-plane $v(\mathrm{C}-\mathrm{H})_{\text {ring }}$ modes. At such a low temperature it is unlikely that any chemical transformations of the adsorbed anisole have occurred; thus, these intensity changes must be due to the orientation of the chemisorbed anisole relative to the more random orientation for the physisorbed species. In particular, the decrease in the intensities of the peaks for in-plane modes relative to those for out-of-plane modes indicates that the aromatic ring is situated parallel to the surface in the 
chemisorbed species. This conclusion relies on the fact that an induced image dipole in the metal partially shields vibrational modes which have dipole moments parallel to the surface, thereby decreasing their HREELS cross-section. It is also consistent with DFT studies of the interaction of anisole with $\operatorname{Pt}(111)$ reported by Bonalumi et al. [36, 37] which showed that the aromatic ring in anisole adsorbs in the same bridge site in which benzene adsorbs on this surface [38]. In this configuration the $\mathrm{O}-\mathrm{CH}_{3}$ group is slightly tilted away from the surface.

Further heating the anisole-dosed $\mathrm{Pt}(111)$ surface to $250 \mathrm{~K}$ and then $300 \mathrm{~K}$ led to significant changes in the HREEL spectrum. These include a large decrease in the intensity of the ring breathing mode at 780 $\mathrm{cm}^{-1}$, the further emergence of an intense peak at $825 \mathrm{~cm}^{-1}$ and smaller peaks at 1630 and $1750 \mathrm{~cm}^{-1}$. Changes were also observed in the $\mathrm{C}-\mathrm{H}$ stretching region of the spectrum with the intensity of the $v(\mathrm{C}-\mathrm{H})_{\text {ring }}$ mode decreasing relative to that of the aliphatic $v(\mathrm{C}-\mathrm{H})$ mode at $2870 \mathrm{~cm}^{-1}$. These signify that reaction or decomposition of the adsorbed anisole has started to occur by $300 \mathrm{~K}$. While it is difficult to unambiguously assign the spectrum at this temperature to specific specie(s), the large decrease in the intensity of the ring breathing mode and the change in the relative intensities of the aromatic and aliphatic $v(\mathrm{C}-\mathrm{H})$ modes suggests a loss of aromatic character for at least a portion of the adsorbed intermediates.

Even more dramatic changes occurred in the HREEL spectrum obtained upon heating the sample to $350 \mathrm{~K}$. At this temperature the spectrum was dominated by an intense peak at $825 \mathrm{~cm}^{-1}$. Smaller peaks are also apparent at 470, 1750, 2000, and $2870 \mathrm{~cm}^{-1}$, as well as several poorly resolved peaks between 1000 and $1450 \mathrm{~cm}^{-1}$. The peak at $2000 \mathrm{~cm}^{-1}$ can be assigned to $\mathrm{CO}$ adsorbed in atop sites and indicates that some C-C bond cleavage has started to occur by this temperature. We also assign the peak at $1750 \mathrm{~cm}^{-1}$ to adsorbed $\mathrm{CO}$ but in bridging sites. While this is an unusually low frequency for bridging $\mathrm{CO}$, previous studies have shown that co-adsorbed electron-donating molecules, such as benzene, can cause a significant decrease in the $\mathrm{C}-\mathrm{O}$ stretching frequency by increasing the amount of back donation of $d$-electrons from the metal into the $\pi^{*}$ anti-bonding orbitals of the adsorbed CO [39, 40]. We believe that something similar is happening here. The fact that this peak shifts to $1800 \mathrm{~cm}^{-1}$ upon heating to higher temperatures which causes complete decomposition of the anisole reactant is also consistent with this explanation. It is noteworthy that with the exception of these $v(\mathrm{CO})$ peaks, the HREEL spectrum at this temperature is nearly identical to that reported by $\mathrm{Ihm}$ and White for an oxocyclohexadienyl intermediate $\left(\mathrm{C}_{6} \mathrm{H}_{6} \mathrm{O}, 2,5\right.$-cyclohexadienone) that is formed by reaction of phenol on $\operatorname{Pt}(111)$ [41]. In that study it was shown that this species bonds to the surface in an $\eta_{5}-\pi$ configuration. To further illustrate this similarity we collected HREEL spectra for a phenol-dosed Pt(111) surface and the spectrum obtained after heating to $400 \mathrm{~K}$ is included in the supplemental information. We, therefore, propose that an oxocyclohexadienyl species is also formed via the reaction of anisole on $\operatorname{Pt}(111)$. The 
near disappearance of the characteristic aromatic C-H stretch near $3000 \mathrm{~cm}^{-1}$ is also consistent with this conclusion. We also note that the $v(\mathrm{C}-\mathrm{O})$ mode

Formation of an oxocyclohexadienyl intermediate requires cleavage of the $\mathrm{O}-\mathrm{CH}_{3}$ bond in anisole and the addition of an $\mathrm{H}$ atom to the ring. The $\mathrm{O}-\mathrm{CH}_{3}$ bond cleavage would also produce adsorbed methyl groups. Previous studies of the interaction of methyl groups with $\operatorname{Pt}(111)$ show that they are unstable on this surface above $230 \mathrm{~K}$ and undergo dehydrogenation to produce adsorbed $\mathrm{C}$ and $\mathrm{H}$ [42]; thus, the desorption-limited $\mathrm{H}_{2}$ peak at $350 \mathrm{~K}$ in the TPD data in Fig. 1 can be attributed to the $\mathrm{H}$ formed by this dehydrogenation reaction. The peak at $470 \mathrm{~cm}^{-1}$ in the HREEL spectrum that appears after heating to 350 $\mathrm{K}$ can be assigned to a Pt-C stretch of the associated carbon atoms.

Heating the anisole-dosed $\mathrm{Pt}(111)$ sample above $350 \mathrm{~K}$ caused the gradual disappearance of the vibrational peaks associated with adsorbed hydrocarbon intermediates with the peaks for adsorbed $\mathrm{CO}$ persisting up to $500 \mathrm{~K}$. This result along with the simultaneous $\mathrm{H}_{2}$ and $\mathrm{CO}$ peaks at $480 \mathrm{~K}$ in the anisole TPD data (Fig. 1) indicate that the oxocyclohexadienyl intermediate undergoes unselective decomposition near this temperature. This would produce small $\mathrm{CH}_{\mathrm{x}}$ fragments that apparently undergo further dehydrogenation at higher temperatures giving rise to the broad $\mathrm{H}_{2}$ desorption feature between 550 and $750 \mathrm{~K}$.

The HREELS data do not provide much insight into the origin of the $420 \mathrm{~K} \mathrm{CO}$ peak in the anisole/Pt(111) TPD data. We can speculate, however, to its origin. It is possible that cleavage of either $\mathrm{C}-\mathrm{O}$ bond in adsorbed anisole may occur. As discussed above, $\mathrm{O}-\mathrm{CH}_{3}$ bond cleavage results in the formation of oxocyclohexadienyl as indicated by HREELS. In contrast, cleavage of the $\mathrm{Ph}-\mathrm{O}(\mathrm{Ph}=$ phenyl group) bond would produce an adsorbed phenyl group and an adsorbed methoxy group. At the temperature at which this reaction occurs it is likely that the methoxy group would rapidly decompose which could give rise to the $420 \mathrm{~K}$ desorption-limited CO peak. Decomposition of the phenyl group could contribute to the higher temperature $\mathrm{H}_{2}$ desorption features. The reaction pathways for anisole on $\mathrm{Pt}(111)$ as determined from the TPD and HREELS data are summarized in Fig. 3.

\subsection{Reaction of anisole on $\mathrm{Zn} / \mathrm{Pt}(111)$}

Consistent with our previous studies of the reactivity of Zn-decorated $\operatorname{Pt}(111)$ surfaces [24, 43], adding $0.2 \mathrm{ML}$ of $\mathrm{Zn}$ adatoms to the $\mathrm{Pt}(111)$ surface significantly altered its reactivity towards anisole. TPD data obtained from 0.2 ML Zn/Pt(111) dosed with 0.6 L of anisole are displayed in Fig. 4. For this surface in addition to anisole, $\mathrm{H}_{2}$ and $\mathrm{CO}$, a range of other products were detected including $\mathrm{CH}_{4}, \mathrm{CH}_{2} \mathrm{O}$, and $\mathrm{C}_{2} \mathrm{H}_{6}$. The low-temperature anisole desorption features were similar to those obtained from $\mathrm{Zn}$-free $\mathrm{Pt}(111)$. Hydrogen primarily desorbed in two peaks centered at 450 and $500 \mathrm{~K}$, and $\mathrm{CO}$ in a single peak at $500 \mathrm{~K}$. Note that the large $\mathrm{H}_{2}$ peak at $350 \mathrm{~K}$ for $\mathrm{Pt}(111)$ is nearly absent for $\mathrm{Zn} / \mathrm{Pt}(111)$, and the onset of 
the primary $\mathrm{H}_{2}$ and $\mathrm{CO}$ desorption features occurs at significantly higher temperatures $(>100 \mathrm{~K})$ on the $\mathrm{Zn}$-modified surface. This indicates that $\mathrm{Zn}$ addition decreases the activity for $\mathrm{C}-\mathrm{H}$ and $\mathrm{C}-\mathrm{C}$ bond scission resulting in the adsorbed species derived from anisole being more stable on the $\mathrm{Zn}$-modified surface. The observation of additional products from $\mathrm{Zn} / \mathrm{Pt}(111)$ also indicates that the reactions on this surface are more selective. The $\mathrm{CH}_{2} \mathrm{O}$ produced at $445 \mathrm{~K}$ likely results from cleavage of the $\mathrm{Ph}-\mathrm{O}$ bond followed by dehydrogenation of the resulting methoxide group. Note that during methanol TPD on $\mathrm{Zn} / \mathrm{Pt}(111), \mathrm{CH}_{2} \mathrm{O}$ is also produced near $445 \mathrm{~K}$ and previous studies have shown that this is a desorption-limited product [44]. Thus, in the case of anisole, $\mathrm{Ph}-\mathrm{O}$ bond cleavage must occur below $445 \mathrm{~K}$. Note that the $\mathrm{Ph}-\mathrm{O}$ bond cleavage would also produce an adsorbed phenyl group and hydrogenation of this species could account for the small amount of benzene produced at $450 \mathrm{~K}$.

HREEL spectra as a function of temperature for anisole-dosed $\mathrm{Zn} / \mathrm{Pt}(111)$ are displayed in Fig. 5. As expected, at temperatures below $190 \mathrm{~K}$ the spectrum is nearly identical to that obtained in this temperature range for $\mathrm{Zn}$-free $\mathrm{Pt}(111)$ and is consistent with IR and Raman spectra for anisole (see Table 1) [33-35]. Heating to $215 \mathrm{~K}$, which is sufficient to desorb physisorbed anisole, caused some changes including the emergence of a small peak at $400 \mathrm{~cm}^{-1}$, a large increase in the intensity of the $\delta(\mathrm{C}-\mathrm{H})_{\text {ring }}$ peak at $1000 \mathrm{~cm}^{-1}$, and a decrease in the intensities of the $v(\mathrm{C}-\mathrm{H})$ peaks at 2880 and $3000 \mathrm{~cm}^{-1}$. The peak at $400 \mathrm{~cm}^{-1}$ is at a position typically observed for metal-oxygen stretching modes [44-47]. In our previous study of the reaction of methanol on $\mathrm{Zn} / \mathrm{Pt}(111)$, methoxide groups adsorbed on $\mathrm{Zn}$ sites also had a $v(\mathrm{Zn}$ O) stretch at this energy. This indicates that some adsorbed anisole binds to $\mathrm{Zn}$ sites on the surface via the oxygen.

Comparing the HREEL spectra for adsorbed anisole obtained near $200 \mathrm{~K}$ for both the $\mathrm{Pt}(111)$ and $\mathrm{Zn} / \mathrm{Pt}(111)$ surfaces reveals that there is prominent peak at $1000 \mathrm{~cm}^{-1}$ in the spectrum from $\mathrm{Zn} / \mathrm{Pt}(111)$ which is nearly absent in that from $\mathrm{Pt}(111)$. This peak is at the expected position for the in-plane $\delta(\mathrm{C}-\mathrm{H})_{\text {ring }}$ mode of anisole. As discussed above, the absence of this in-plane mode in the $\mathrm{Pt}(111)$ spectrum at $200 \mathrm{~K}$ can be attributed to the aromatic ring being situated nearly parallel to the surface. In the case of $\mathrm{Zn} / \mathrm{Pt}(111)$ the intensity of this peak indicates that the ring is tilted away from this surface. Note that this conclusion is consistent with what we have reported previously for the interaction of benzaldehyde with $\mathrm{Pt}(111)$ and $\mathrm{Zn} / \mathrm{Pt}(111)$ surfaces [24]. Thus, based on the HREELS data we propose that on $\mathrm{Zn} / \mathrm{Pt}(111)$ anisole adsorbs via the oxygen as shown in Fig. 3, with the phenyl ring tilted away from the surface

When the anisole-dosed $\mathrm{Zn} / \mathrm{Pt}(111)$ surface was heated to $250 \mathrm{~K}$, only minor changes occurred in the HREEL spectrum including further increases in the intensities of the peaks at 400 and $1000 \mathrm{~cm}^{-1}$ and a change in the relative intensities of the aliphatic and aromatic $v(\mathrm{C}-\mathrm{H})$ peaks between 2800 to $3100 \mathrm{~cm}^{-1}$. Also note that the high intensity of the peak at $1000 \mathrm{~cm}^{-1}$ relative to the other peaks suggests that modes in addition to the in-plane $\delta(\mathrm{C}-\mathrm{H})_{\text {ring }}$ mode of anisole are contributing to this peak. Since C-O stretches of 
alkoxide groups are relatively intense and typically located near this energy [45-49], we propose that the $v(\mathrm{C}-\mathrm{O})$ mode of methoxide groups formed via cleavage of the $\mathrm{Ph}-\mathrm{O}$ bond in a portion of the adsorbed anisole contributes to the peak at $1000 \mathrm{~cm}^{-1}$. This reaction would also produce an adsorbed phenyl group.

Heating the sample to 300 and then $350 \mathrm{~K}$ produced additional changes with the HREEL spectrum becoming dominated by the peaks at 400 and $1000 \mathrm{~cm}^{-1}$ and all the other peaks becoming less intense. A small $v(\mathrm{C}-\mathrm{O})$ stretch at $2000 \mathrm{~cm}^{-1}$ also grows in which may be due in part to adsorption of some CO from the background. It is noteworthy that the spectrum at this temperature is nearly identical to that reported for methoxide groups adsorbed on this surface [44] which further supports the conclusion that C-O bond cleavage has occurred producing adsorbed methoxide. The persistence of the characteristic aromatic $v(\mathrm{C}-\mathrm{H})$ peak at $3000 \mathrm{~cm}^{-1}$, however, indicates that phenyl groups remain on the surface. At least a portion of these phenyl groups react to produce benzene that desorbs at $450 \mathrm{~K}$ as observed in the TPD data. Additional heating to $450 \mathrm{~K}$ resulted in the disappearance of the peaks associated with adsorbed hydrocarbon intermediates and the growth of the $v(\mathrm{C}-\mathrm{O})$ stretch at $2000 \mathrm{~cm}^{-1}$ due to adsorbed $\mathrm{CO}$.

The HREELS results for $\mathrm{Zn} / \mathrm{Pt}(111)$ provide strong evidence for selective cleavage of the $\mathrm{Ph}-\mathrm{O}$ bond in anisole to produce adsorbed methoxide and phenyl. While cleavage of the $\mathrm{O}-\mathrm{CH}_{3}$ bond in at least a portion of the absorbed anisole cannot be completely ruled out, the HREELS data do not provide any evidence for phenoxide or the oxocyclohexadienyl intermediate that was formed on the $\mathrm{Zn}$-free $\mathrm{Pt}(111)$. As noted above, we have previously studied the reaction of $\mathrm{CH}_{3} \mathrm{OH}$ on $\mathrm{Zn} / \mathrm{Pt}(111)$ and in that study it was observed that methoxide groups formed by dissociative adsorption of methanol also reacted to form $\mathrm{CH}_{2} \mathrm{O}$ which desorbed $440 \mathrm{~K}$ [44]. XPS and HREELS results indicated that the methoxide groups involved in this reaction were adsorbed on $\mathrm{Zn}$ sites. Methanol TPD data as a function of $\mathrm{Zn}$ coverage also showed that the area of the $440 \mathrm{~K} \mathrm{CH}_{2} \mathrm{O}$ peak went through a maximum near $0.4 \mathrm{ML}$ of $\mathrm{Zn}$ and disappeared for $\mathrm{Zn}$ coverages greater than $0.8 \mathrm{ML}$ indicating that the initial dissociative adsorption of $\mathrm{CH}_{3} \mathrm{OH}$ does not occur directly on the $\mathrm{Zn}$ sites, but rather on adjacent $\mathrm{Pt}$ sites whose electronic properties are modified by $\mathrm{Zn}$ adatoms. As has been shown in several previous studies [22-24, 43], Pt-Zn interactions decrease the activity of the Pt surface for C-C and C-H bond activation resulting in adsorbed oxygenate and hydrocarbon intermediates being more stable on Zn-modified Pt compared to Zn-free Pt. Based on these previous results for methanol, we propose a similar scenario for the adsorption and reaction of anisole on $\mathrm{Zn} / \mathrm{Pt}(111)$ with the initial chemisorption at low temperature occurring primarily on $\mathrm{Pt}$ sites adjacent to $\mathrm{Zn}$ adatoms. Selective cleavage of the $\mathrm{Ph}-\mathrm{O}$ bond in these adsorbed anisole molecules produces methoxide groups that are bonded to the $\mathrm{Zn}$ atoms and phenyl groups bonded to adjacent $\mathrm{Pt}$ sites. This reaction pathway is shown in Fig. 3.

It is somewhat more difficult to account for the $\mathrm{CO}, \mathrm{CH}_{4}$ and $\mathrm{H}_{2}$ products that desorb at $500 \mathrm{~K}$ from the anisole-dosed $\mathrm{Zn} / \mathrm{Pt}(111)$ surface. The fact that these products are all produced at the same 
temperature indicates that they are reaction-limited and result from the decomposition of a common intermediate. While the HREELS data do not provide much insight into what this intermediate may be, it is possible that unselective decomposition of anisole occurs on non $\mathrm{Zn}$-modified portions of the surface producing adsorbed hydrocarbon fragments that undergo further decomposition near this temperature.

\subsection{Reactor Studies}

The studies of the interaction of anisole with the model catalysts demonstrate that $\mathrm{Zn}$ addition to the $\operatorname{Pt}(111)$ surface affects reactivity in several ways, including altering the strength of the interaction of the phenyl ring with the surface, altering the barriers for $\mathrm{C}-\mathrm{H}$ and $\mathrm{C}-\mathrm{C}$ bond cleavage, and providing sites that are selective for $\mathrm{C}-\mathrm{O}$ bond cleavage. On $\mathrm{Zn}$-free $\mathrm{Pt}(111)$ there is a strong interaction between the phenyl ring and the surface resulting in a bonding geometry in which the ring is situated parallel to the surface. Anisole adsorbed in this configuration undergoes $\mathrm{C}-\mathrm{O}$ and $\mathrm{C}-\mathrm{H}$ bond scission at low temperatures to produce oxocyclohexadienyl and methyl groups with the former ultimately decomposing to produce $\mathrm{CO}$, $\mathrm{H}_{2}$ and small $\mathrm{CH}_{\mathrm{x}}$ fragments. In contrast, on $\mathrm{Zn}$-modified $\mathrm{Pt}(111)$ a different adsorption configuration and reaction pathway for anisole were observed. As has been reported previously in our benzaldehyde study [24], through an electronic interaction the $\mathrm{Zn}$ decreases the adsorption energy of the phenyl ring with the surface. This causes the preferred adsorption geometry to be one in which the phenyl ring is tilted away from the surface with bonding occurring primarily via the oxygen. Selective C-O bond scission in this

species at or near $\mathrm{Zn}$ sites produces adsorbed phenyl groups and methoxide groups with the latter being bonded to the $\mathrm{Zn}$ sites. While cleavage of the $\mathrm{O}-\mathrm{CH}_{3}$ bond to produce phenoxide groups might also occur, the TPD and HREELS results did not provide direct evidence for this pathway. These reaction pathways are summarized in Fig. 3.

Based on the results obtained from the model catalysts one can speculate as to how the reactivity of supported Pt and Pt-Zn catalysts may differ for the HDO of anisole. Since the reaction of anisole on $\mathrm{Pt}(111)$ was not found to be selective for $\mathrm{C}-\mathrm{O}$ bond cleavage, one would not expect high surface area $\mathrm{Pt}$ catalysts to be particularly selective for the reaction of anisole to produce benzene or phenol. The adsorption configuration of anisole on $\mathrm{Pt}(111)$ in which the phenyl ring lays flat on the surface may also help facilitate hydrogenation of the ring under typical HDO reaction conditions where there is a high partial pressure of $\mathrm{H}_{2}$. Thus, one might also expect Pt catalysts to produce ring hydrogenation products for these conditions which are generally undesired since aromatic compounds have higher values. Since modifying $\mathrm{Pt}(111)$ with $\mathrm{Zn}$ changes the bonding configuration of anisole to one in which the primary interaction is via the oxygen with the phenyl ring tilted away from the surface, one would expect Pt-Zn catalysts to be less likely to promote ring hydrogenation under HDO conditions. The results obtained from $\mathrm{Zn} / \mathrm{Pt}(111)$ also indicate that $\mathrm{Zn}$ provides sites that are selective for $\mathrm{C}-\mathrm{O}$ bond cleavage as evidenced 
by the production of methoxide, as determined by HREELS, and benzene which was observed as product during TPD. These observations along with the fact that $\mathrm{Zn}$ addition appears to lower the activity of the Pt surface for C-C bond cleavage [22, 24, 43], suggests that high surface area Pt-Zn catalysts have some promise for the HDO of lignin-derived oxygenates to produce aromatic compounds.

In order to verify these predictions from the model catalyst results, we evaluated the performance of carbon-supported $\mathrm{Pt}$ and $\mathrm{Pt}-\mathrm{Zn}$ catalysts for $\mathrm{HDO}$ of anisole using a tubular flow reactor. Details of the catalyst synthesis and reactor configuration are given in the experimental section. Conversion and product distributions for $\mathrm{Pt} / \mathrm{C}$ and $\mathrm{PtZn} / \mathrm{C}$ catalysts at a reaction temperature of $598 \mathrm{~K}$ are shown in Fig. 6. Note that only the condensable products were collected and analyzed and no ring opening products were detected. Also note that in addition to the products listed, some methane was likely produced.

As shown in Fig. 6, at a space time of $0.5 \mathrm{~g} \cdot \mathrm{min} \cdot \mathrm{ml}^{-1}$ the anisole conversion over $10 \mathrm{wt} \% \mathrm{Pt} / \mathrm{C}$ was $75 \%$ with a high selectivity to methoxycyclohexane which made up $74 \%$ of the condensable product. Smaller amounts of demethylation products, cyclohexane and cyclohexanol, were also produced. In order to determine the product selectivity at lower conversion (i.e. closer to differential reaction conditions) and to determine if any other intermediate products were produced, experiments were also performed for a 1 wt $\% \mathrm{Pt} / \mathrm{C}$ catalyst with a reactant space time of $0.17 \mathrm{~g} \cdot \mathrm{min} \cdot \mathrm{ml}^{-1}$. For these conditions the anisole conversion was only $31 \%$ but the selectivity to methoxycyclohexane increased to $88 \%$ and only small amounts of demethylation products, cyclohexane, cyclohexanone, and cyclohexanol, were produced. Using these data and an average Pt particle size as determined by TEM, the turnover frequency (TOF) for these reaction conditions is estimated to be $0.22 \mathrm{~s}^{-1}$. This value is similar to that reported previously, $0.104 \mathrm{~s}^{-1}$, for the gas phase $\mathrm{HDO}$ of anisole over a $\mathrm{Pt} / \mathrm{SiO}_{2}$ catalyst [25]. The increase in methoxycyclohexane selectivity with decreasing space time at the expense of the products requiring demethylation suggests that demethylation occurs after ring hydrogenation. Thus, on the $\mathrm{Pt} / \mathrm{C}$ catalyst hydrogenation of the phenyl ring appears to be rather facile. This observation is consistent with the model catalyst studies which demonstrated an adsorption configuration for anisole on $\operatorname{Pt}(111)$ that would facilitate its hydrogenation, namely bonding via the $\pi$-orbitals of the phenyl ring with the ring lying flat on the surface. Thus, as predicted by the model catalysts studies, Pt/C has high activity for ring hydrogenation and low activity for selective $\mathrm{C}-\mathrm{O}$ bond scission.

The conversion and product selectivity data for the $10 \mathrm{wt} \% \mathrm{PtZn} / \mathrm{C}$ catalyst at a reactant space time of $0.5 \mathrm{~g} \cdot \mathrm{min} \cdot \mathrm{ml}^{-1}$ are also presented in Fig. 6. These data show that, as expected, alloying Pt with $\mathrm{Zn}$ significantly alters reactivity. The $\mathrm{PtZn} / \mathrm{C}$ catalyst has lower overall activity with the anisole conversion being less than half that obtained for $\mathrm{Pt} / \mathrm{C}$ at similar reaction conditions (corresponding to a TOF of 0.013 $\mathrm{s}^{-1}$ which was estimated assuming the same average particle size as the $\mathrm{Pt} / \mathrm{C}$ catalyst). The PtZn/C catalyst is also highly selective for the production of phenol which represented $66 \%$ of the condensable product. 
Products requiring phenyl ring hydrogenation were also produced, most notably cyclohexane and cyclohexanol, but accounted for only $\sim 27 \%$ of the condensable products.

It is likely that the co-impregnation method used to synthesize the Pt-Zn catalyst would produce metal particles with a range of $\mathrm{Pt}: \mathrm{Zn}$ ratios. Since the $\mathrm{Pt} / \mathrm{C}$ catalyst was highly active for phenyl ring hydrogenation it is possible that for the $\mathrm{PtZn} / \mathrm{C}$ catalyst the ring hydrogenation products were produced on Pt-rich particles. To investigate this possibility and to assess the effect of $\mathrm{Zn}$ content on reactivity, reactor studies were also performed for a $10 \mathrm{wt} \% \mathrm{PtZn}_{3} / \mathrm{C}$ catalyst which had a Pt:Zn ratio of 1:3. Conversion and product selectivity data as a function of reaction temperature for this catalyst are presented in Fig. $7\left(\mathrm{~W} / \mathrm{F}=0.5 \mathrm{~g} \cdot \mathrm{min} \cdot \mathrm{ml}^{-1}, \mathrm{P}\left(\mathrm{H}_{2}\right)=27.5 \mathrm{bar}\right)$. These data show that increasing the $\mathrm{Zn}$ content dramatically decreased overall activity with only $10 \%$ conversion at $598 \mathrm{~K}$, but increased the selectivity to phenol to nearly $91 \%$. Increasing the temperature to 623 and $648 \mathrm{~K}$ resulted in an increase in conversion but the high selectivity to phenol was maintained. These results support the possibility that in the case of the Pt-Zn catalyst the ring hydrogenation products were produced on Pt-rich particles.

It is important to note that while selective C-O bond scission was observed for both the model and high surface area PtZn catalysts, a different $\mathrm{C}-\mathrm{O}$ bond was cleaved in each case. On $\mathrm{Zn} / \mathrm{Pt}(111)$ cleavage of the $\mathrm{Ph}-\mathrm{O}$ bond resulted in the production of benzene, while $\mathrm{PtZn} / \mathrm{C}$ was selective for the less-desirable cleavage of the $\mathrm{O}-\mathrm{CH}_{3}$ bond leading to the production of phenol. The origin of this discrepancy is not clear, but the disparate reaction conditions between the UHV and reactor studies, i.e. presence of a solvent ( $n$-heptane) and a high pressure of $\mathrm{H}_{2}$ in the case of the reactor studies, may have played a role. The surface structures of the model and high surface area catalysts are also likely to be much different. Nonetheless, it is interesting that in both cases the addition of $\mathrm{Zn}$ increases the selectivity for $\mathrm{C}-\mathrm{O}$ bond cleavage and based on the model catalyst studies this appears to be due to surface $\mathrm{Zn}$ atoms providing a binding site for the oxygen in the anisole reactant.

\section{Summary}

The combined surface science and reactor studies provide considerable insight into both the reactivity of aromatic oxygenates on $\mathrm{Pt}$ and how alloying with a second more oxyphilic metal, such as $\mathrm{Zn}$, can be used to alter the reactivity and increase the selectivity for $\mathrm{C}-\mathrm{O}$ bond cleavage which is required for HDO of this class of molecules. As described in the introduction, previous studies have suggested that alloying Pt with a more oxyphilic metal decreases the strength of the interaction of aromatic rings with the Pt surface [19-21]. The results obtained here show this quite dramatically for anisole where binding on $\operatorname{Pt}(111)$ occurs primarily via the $\pi$-orbitals of the phenyl ring with the ring situated parallel to the surface, while on $\mathrm{Zn}$-modified $\mathrm{Pt}(111)$ the ring is tilted away from the surface and bonding occurs primarily via the oxygen lone pair electrons on a surface $\mathrm{Zn}$ site or possibly an adjacent Pt site. The reactor studies 
show that this difference in bonding geometry and adsorption sites has a significant effect on reaction selectivity. In particular the bonding geometry on Pt facilitates hydrogenation of the phenyl ring and the $\mathrm{Pt} / \mathrm{C}$ catalyst exhibited high selectivity to saturated products, such as methoxycylohexane and cyclohexane. In contrast on PtZn catalysts for which the model catalyst studies suggested that the phenyl ring will have limited interaction with the surface, ring hydrogenation was greatly suppressed with the primary reaction product being phenol.

The alteration of the interaction of the aromatic rings with the Pt surface appears to be largely an electronic effect of alloying with $\mathrm{Zn}$. The results obtained here and in our previous studies [22-24, 43], however, also show that the oxyphilic nature of the $\mathrm{Zn}$ makes it the preferred binding site for oxygen and an active site for selective $\mathrm{C}-\mathrm{O}$ bond cleavage. This was shown for the $\mathrm{Zn} / \mathrm{Pt}(111)$ model catalyst where Zn-bound methoxide was observed as a primary reaction intermediate and for the high surface area $\mathrm{PtZn/C}$ catalysts which exhibited high selectivity to phenol. Apart from the specific case of PtZn which was investigated here, we believe the results of this study are more generally applicable and help explain why a range of bimetallic catalysts composed of a group 10 metal and a second more oxyphilic metal, e.g. PdZn, PdFe, NiFe, and PtSn [15-18], exhibit promising characteristics as catalysts for the HDO of ligninderived oxygenates to produce high-value aromatic compounds.

\section{Acknowledgements}

Funding for this study was provided by the National Science Foundation grant no. CBET-1508048. 


\section{References}

[1] H. Wang, J. Male, and Y. Wang, ACS Catal. 3 (2013) 1047-1070.

[2] J. Zakzeski, P.C. Bruijnincx, A.L. Jongerius, and B.M. Weckhuysen, Chem. Rev. 110 (2010) 3552-3599.

[3] G.W. Huber, and J.A. Dumesic, Catal. Today 111 (2006) 119-132.

[4] G.W. Huber, S. Iborra, and A. Corma, Chem. Rev.s 106 (2006) 4044-4098.

[5] P. Gallezot, Chem. Soc. Rev. 41 (2012) 1538-1558.

[6] M. Stöcker, Ang. Chemie In. Ed. 47 (2008) 9200-9211.

[7] E. Adler, Wood Sci. Ttech. 11 (1977) 169-218.

[8] D. Mohan, C.U. Pittman, and P.H. Steele, Energy \& Fuels 20 (2006) 848-889.

[9] Q. Bu, H. Lei, A.H. Zacher, L. Wang, S. Ren, J. Liang, Y. Wei, Y. Liu, J. Tang, and Q. Zhang, Bioresource Tech. 124 (2012) 470-477.

[10] A. Centeno, E. Laurent, and B. Delmon, J. Catal. 154 (1995) 288-298.

[11] T.-R. Viljava, R. Komulainen, and A. Krause, Catal. Today 60 (2000) 83-92.

[12] H. Wan, R.V. Chaudhari, and B. Subramaniam, Topics in Catal. 55 (2012) 129-139.

[13] D. Poondi, and M.A. Vannice, J. Catal. 161 (1996) 742-751.

[14] S.D. Lin, and M.A. Vannice, J. Catal. 143 (1993) 539-553.

[15] M.Á. González-Borja, and D.E. Resasco, Energy \& Fuels 25 (2011) 4155-4162.

[16] J. Sun, A.M. Karim, H. Zhang, L. Kovarik, X.S. Li, A.J. Hensley, J.-S. McEwen, and Y. Wang, J. Catal. 306 (2013) 47-57.

[17] T.H. Parsell, B.C. Owen, I. Klein, T.M. Jarrell, C.L. Marcum, L.J. Haupert, L.M. Amundson, H.I. Kenttämaa, F. Ribeiro, and J.T. Miller, Chem. Sci. 4 (2013) 806-813.

[18] S. Leng, X. Wang, X. He, L. Liu, Y.e. Liu, X. Zhong, G. Zhuang, and J.-g. Wang, Catal.s Comm. 41 (2013) 34-37.

[19] C. Xu, Y.L. Tsai, and B.E. Koel, The . Phys. Chem. 98 (1994) 585-593.

[20] J. Breitbach, D. Franke, G. Hamm, C. Becker, and K. Wandelt, Surf. Sci. 507 (2002) 18-22.

[21] G. Hamm, T. Schmidt, J. Breitbach, D. Franke, C. Becker, and K. Wandelt, Surf. Sci. 562 (2004) 170-182.

[22] J.R. McManus, E. Martono, and J.M. Vohs, ACS Catal. 3 (2013) 1739-1750.

[23] J.R. McManus, E. Martono, and J.M. Vohs, Catal. Today 237 (2014) 157-165.

[24] D. Shi, and J.M. Vohs, Surf. Sci. (2015).

[25] X. Zhu, L.L. Lobban, R.G. Mallinson, and D.E. Resasco, J. Catal. 281 (2011) 21-29.

[26] K.L. Deutsch, and B.H. Shanks, Appl. Catal. A 447 (2012) 144-150.

[27] D.J. Rensel, S. Rouvimov, M.E. Gin, and J.C. Hicks, J. Catal. 305 (2013) 256-263.

[28] J.R. McManus, M. Salciccioli, W. Yu, D.G. Vlachos, J.G. Chen, and J.M. Vohs, J. Phys. Chem. C 116 (2012) 18891-18898.

[29] J.R. McManus, and J.M. Vohs, Surf. Sci. 630 (2014) 16-21.

[30] C.-S. Ho, E. Martono, S. Banerjee, J. Roszell, J. Vohs, and B.E. Koel, J. Phys. Chem. A 117 (2013) 11684-11694.

[31] J. Luo, L. Arroyo-Ramírez, R.J. Gorte, D. Tzoulaki, and D.G. Vlachos, AIChE J. 61 (2015) 590597.

[32] R. McCabe, and L. Schmidt, Surf. Sci. 65 (1977) 189-209.

[33] L. Hoffmann, S. Marquardt, A. Gemechu, and H. Baumgärtel, Phys. Chem. Chem.l Phys. 8 (2006) 2360-2377.

[34] D.M. Adams, and A. Squire, J. Chem. Soc. Dalton Transac. (1974) 558-565.

[35] J. Bloino, M. Biczysko, O. Crescenzi, and V. Barone, J. Chem. Phys. 128 (2008) 244105.

[36] N. Bonalumi, A. Vargas, D. Ferri, and A. Baiker, J.f Phys. Chem. B 110 (2006) 9956-9965.

[37] N. Bonalumi, A. Vargas, D. Ferri, T. Bürgi, T. Mallat, and A. Baiker, J. Am. Chem. Soc. 127 (2005) 8467-8477.

[38] M. Saeys, M.-F. Reyniers, G.B. Marin, and M. Neurock, J. Phys. Chem. B 106 (2002) 7489-7498. 
[39] J. Bertolini, G. Dalmai-Imelik, and J. Rousseau, Surf. Sci. 68 (1977) 539-546.

[40] S.H. Pang, A.M. Román, and J.W. Medlin, J. Phys. Chem. C 116 (2012) 13654-13660.

[41] H. Ihm, and J. White, J. Phys. Chem. B 104 (2000) 6202-6211.

[42] D.H. Fairbrother, X. Peng, R. Viswanathan, P. Stair, M. Trenary, and J. Fan, Surf. Sci. 285 (1993) L455-L460.

[43] D. Shi, and J.M. Vohs, ACS Catal. 5 (2015) 2177-2183.

[44] E. Martono, and J.M. Vohs, J. Phys. Chem. C 117 (2013) 6692-6701.

[45] K. Christmann, and J. Demuth, J. Chem. Phys. 76 (1982) 6308-6317.

[46] B.A. Sexton, Surf. Sci. 102 (1981) 271-281.

[47] O. Skoplyak, C.A. Menning, M.A. Barteau, and J.G. Chen, J. Chem. Phys. 127 (2007) 114707114707.

[48] C. Houtman, and M.A. Barteau, Langmuir 6 (1990) 1558-1566.

[49] S.R. Bare, J.A. Stroscio, and W. Ho, Surf. Sci. 150 (1985) 399-418. 


\section{Figure Captions}

Figure 1. TPD spectra obtained following exposure of the $\operatorname{Pt}(111)$ surface to $0.6 \mathrm{~L}$ of anisole.

Figure 2. HREEL spectra as a function of temperature for $\mathrm{Pt}(111)$ dosed with $0.6 \mathrm{~L}$ anisole at $115 \mathrm{~K}$.

Figure 3. Proposed pathways and intermediates for the adsorption and reaction of anisole on $\mathrm{Pt}(111)$ and $\mathrm{Zn} / \mathrm{Pt}(111)$ surfaces

Figure 4. TPD spectra obtained following exposure of the $\mathrm{Zn} / \mathrm{Pt}(111)$ surface to $0.6 \mathrm{~L}$ of anisole.

Figure 5. HREEL spectra as a function of temperature for $\mathrm{Zn} / \mathrm{Pt}(111)$ dosed with $0.6 \mathrm{~L}$ anisole at 115 $\mathrm{K}$.

Figure 6. Product distribution for reaction of anisole on different catalysts under typical HDO conditions: (A) 10 wt \% Pt/C, W/F = $0.5 \mathrm{~g} \cdot \mathrm{min} / \mathrm{ml}$, (B) 1 wt $\% \mathrm{Pt} / \mathrm{C}, \mathrm{W} / \mathrm{F}=0.1667 \mathrm{~g} \cdot \mathrm{min} / \mathrm{ml}$, (C) $10 \mathrm{wt} \% \mathrm{PtZn} / \mathrm{C}, \mathrm{W} / \mathrm{F}=0.5 \mathrm{~g} \cdot \mathrm{min} / \mathrm{ml}$, at $598 \mathrm{~K}$ and $27.5 \mathrm{bar}$.

Figure 7. Product distribution for reaction of anisole on $\mathrm{PtZn}_{3} / \mathrm{C}$ catalyst as a function of temperature. $\mathrm{W} / \mathrm{F}=0.5 \mathrm{~g} * \mathrm{~min} / \mathrm{ml}, 27.5 \mathrm{bar}$ 
Figures

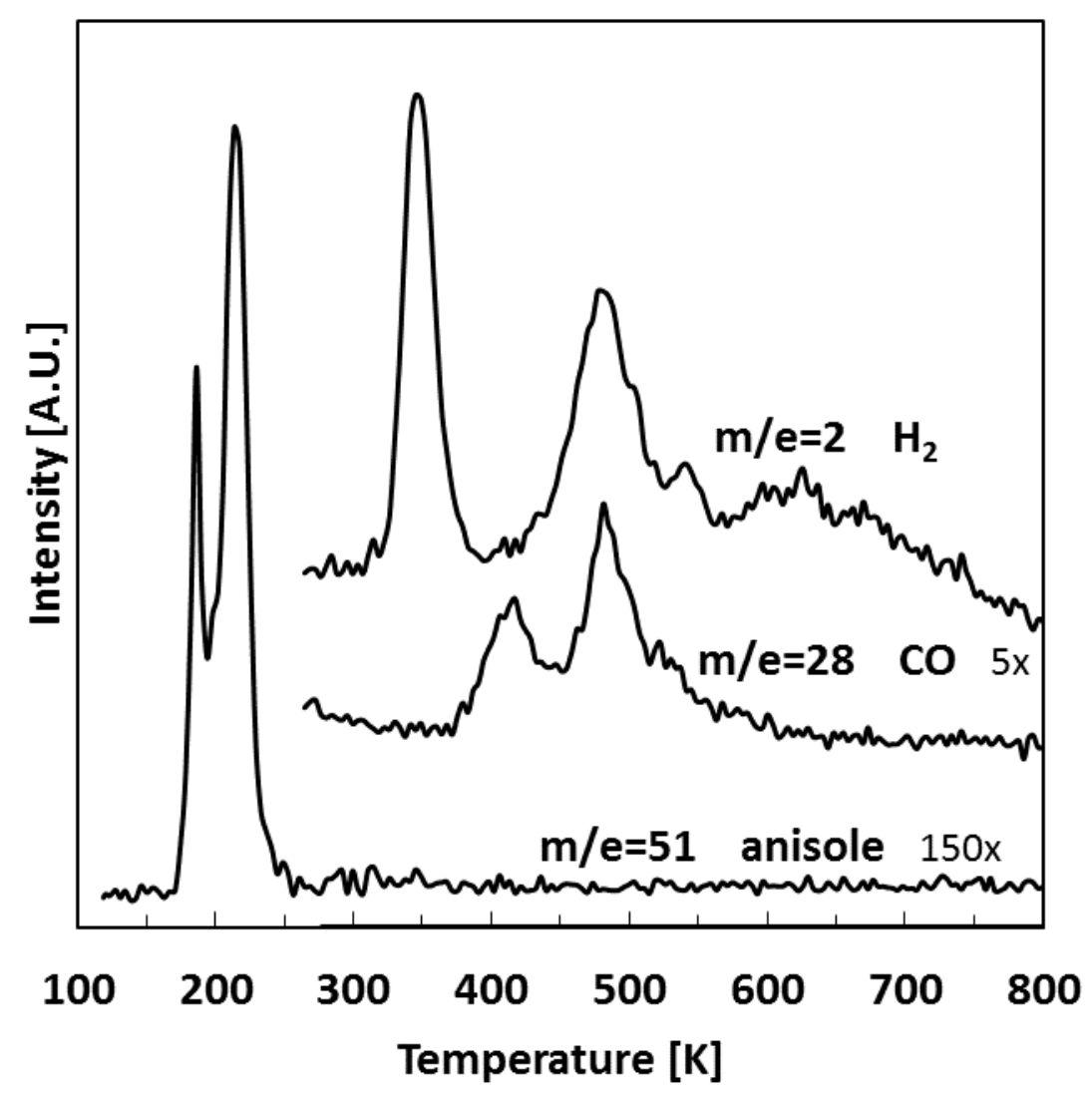

Figure 1. TPD spectra obtained following exposure of the Pt(111) surface to $0.6 \mathrm{~L}$ of anisole. 


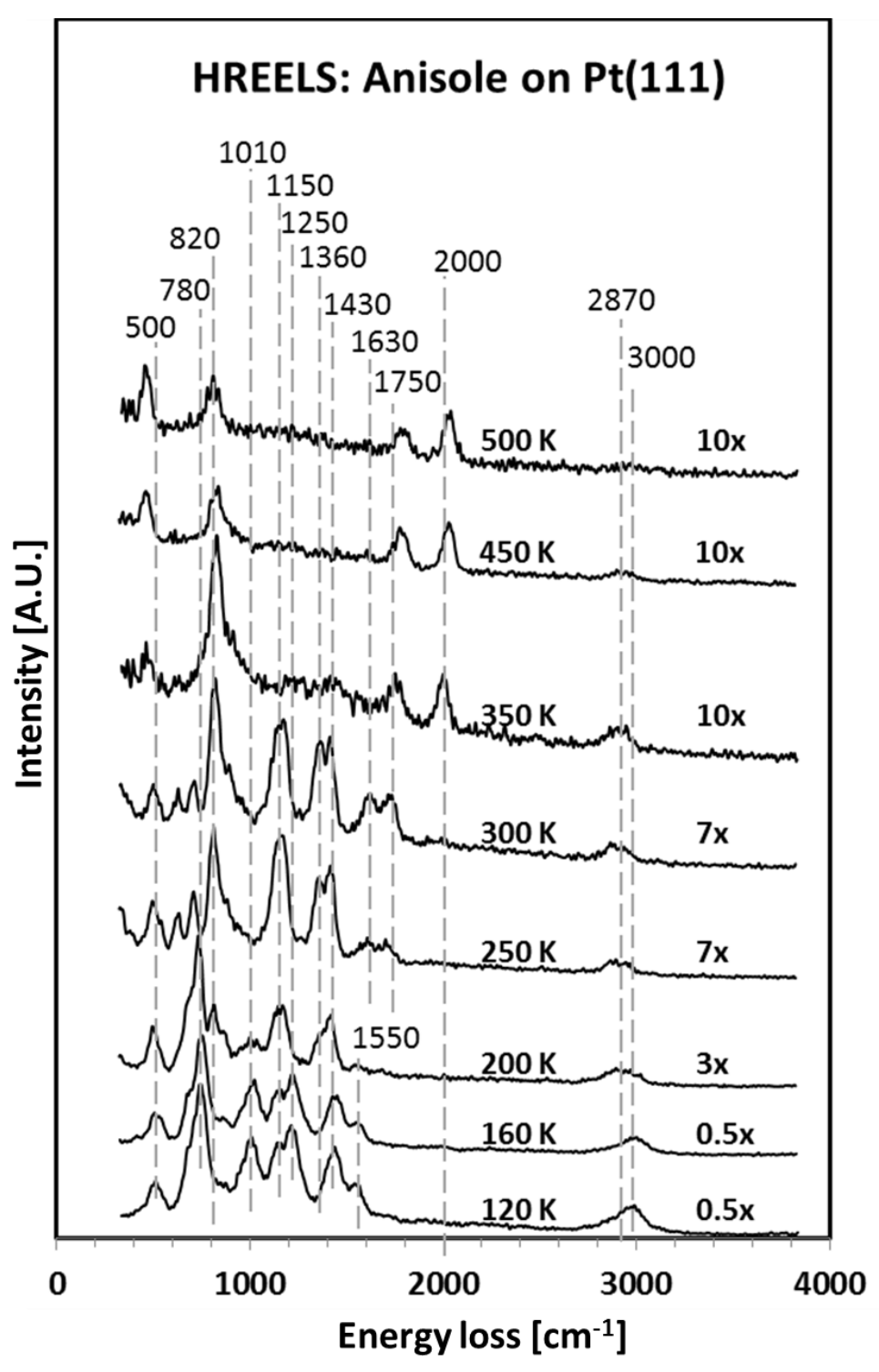

Figure 2. HREEL spectra as a function of temperature for $\mathrm{Pt}(111)$ dosed with $0.6 \mathrm{~L}$ anisole at $115 \mathrm{~K}$. 
Anisole on $\mathrm{Pt}(111)$ surface

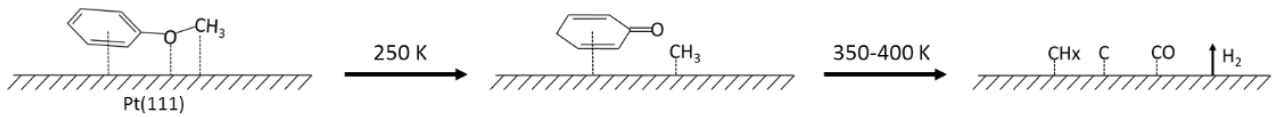

Anisole on $0.2 \mathrm{ML} \mathrm{Zn/Pt(111)} \mathrm{surface}$

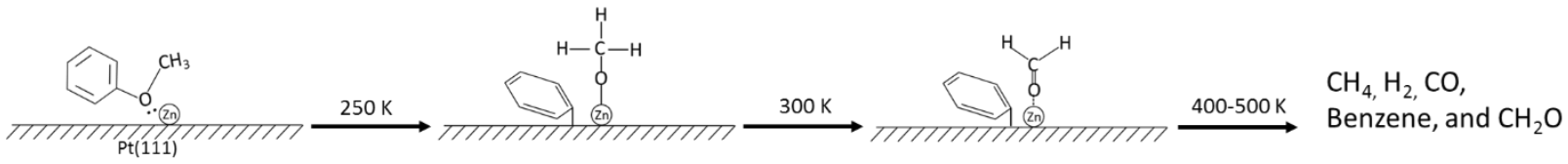

Figure 3. Proposed pathways and intermediates for the adsorption and reaction of anisole on $\mathrm{Pt}(111)$ and $\mathrm{Zn} / \mathrm{Pt}(111)$ surfaces 


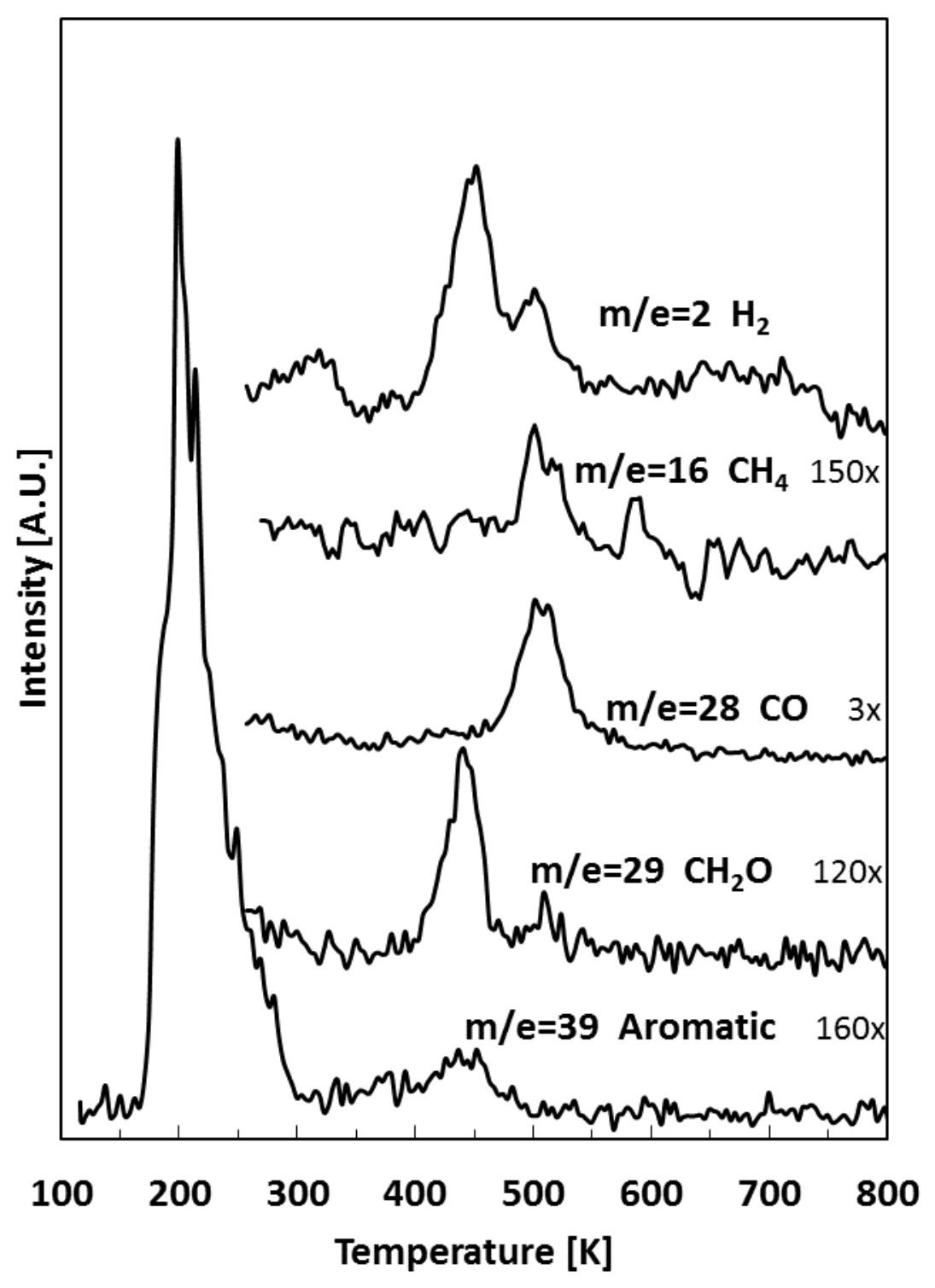

Figure 4. TPD spectra obtained following exposure of the $\mathrm{Zn} / \mathrm{Pt}(111)$ surface to $0.6 \mathrm{~L}$ of anisole. 


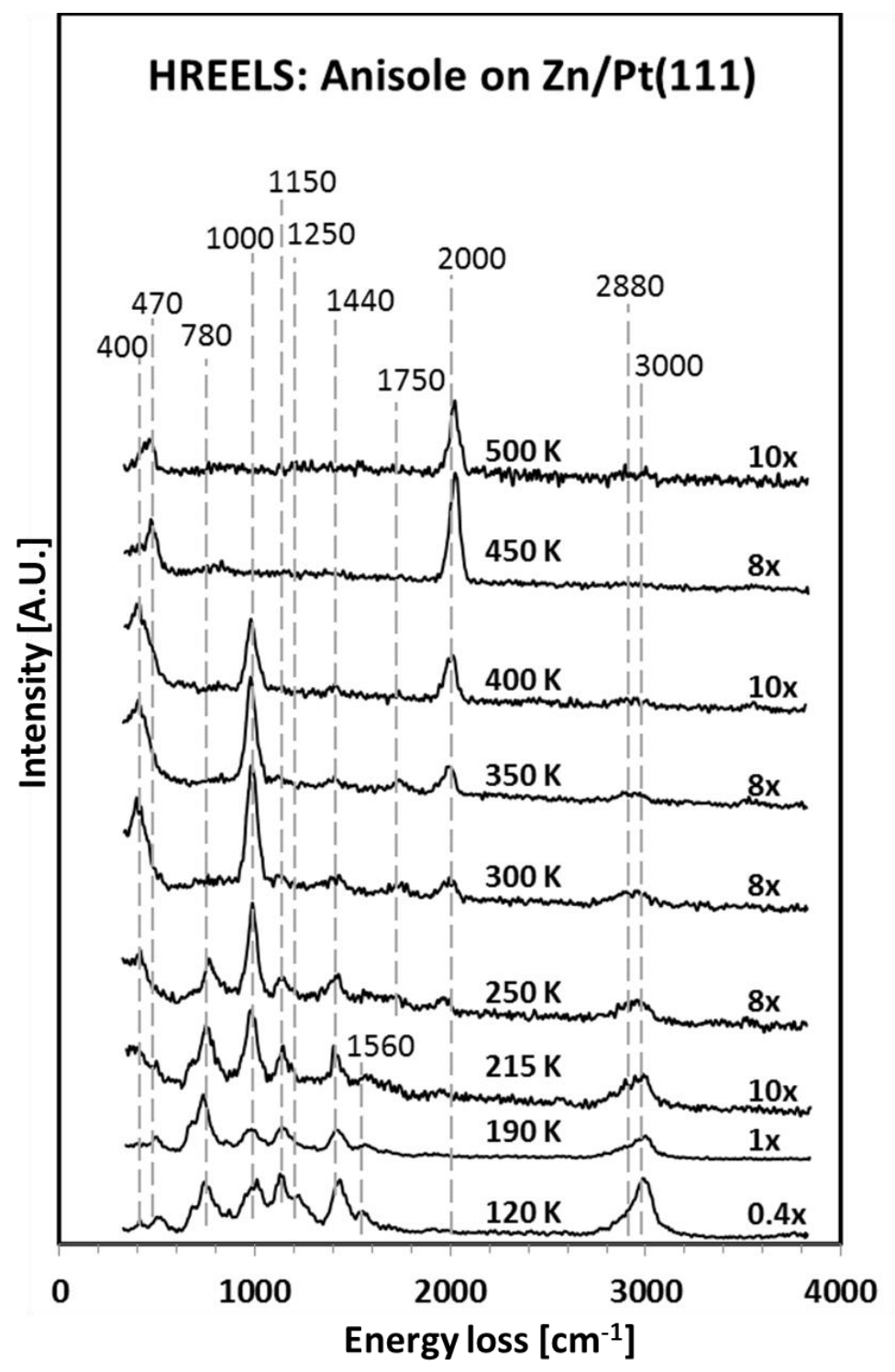

Figure 5. HREEL spectra as a function of temperature for $\mathrm{Zn} / \mathrm{Pt}(111)$ dosed with $0.6 \mathrm{~L}$ anisole at 115 K. 


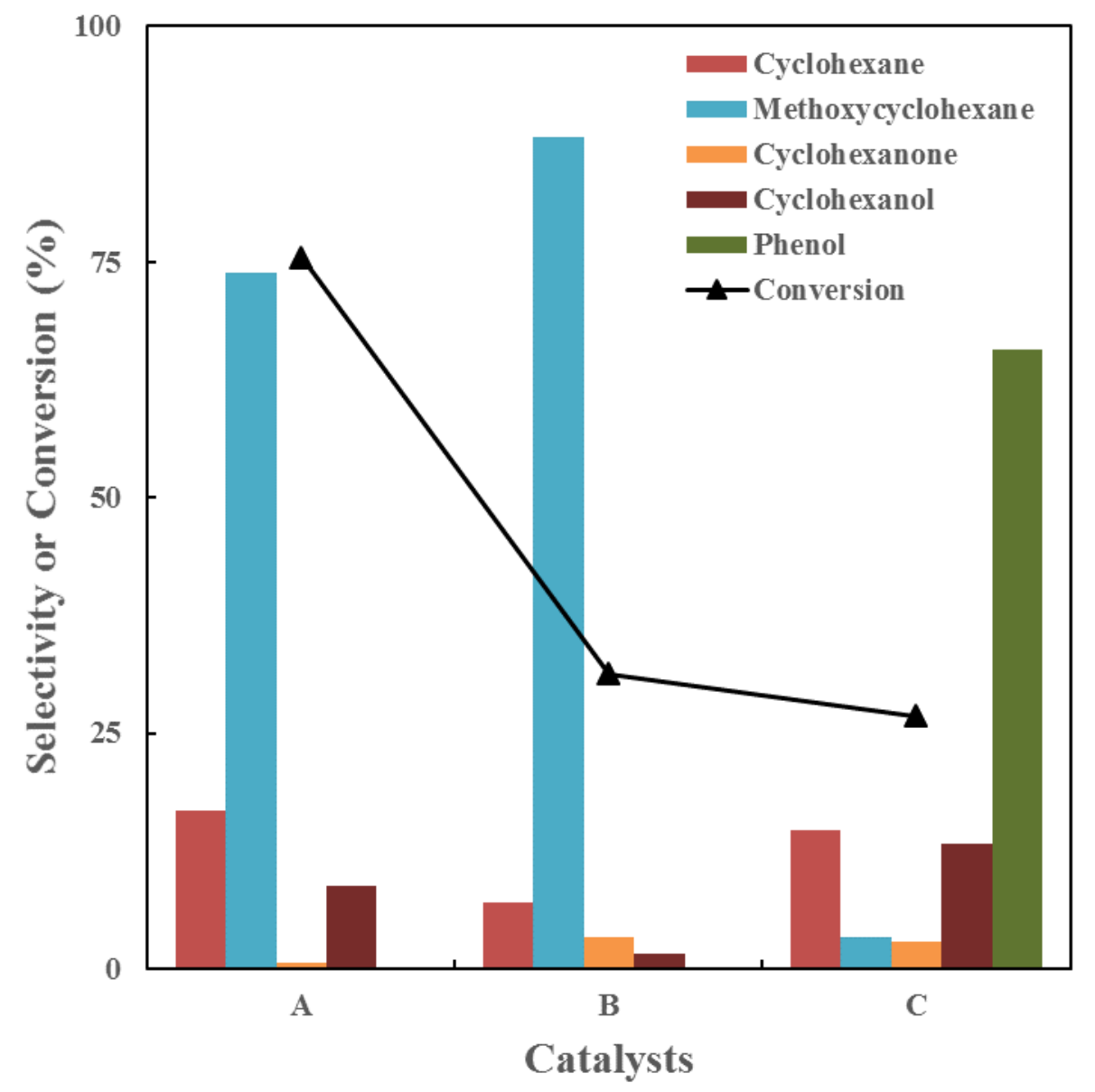

Figure 6. Product distribution for reaction of anisole on different catalysts under typical HDO conditions: (A) $10 \mathrm{wt} \% \mathrm{Pt} / \mathrm{C}, \mathrm{W} / \mathrm{F}=0.5 \mathrm{~g} \cdot \mathrm{min} / \mathrm{ml}$, (B) $1 \mathrm{wt} \% \mathrm{Pt} / \mathrm{C}, \mathrm{W} / \mathrm{F}=0.1667 \mathrm{~g} \cdot \mathrm{min} / \mathrm{ml}$, (C) $10 \mathrm{wt} \% \mathrm{PtZn} / \mathrm{C}, \mathrm{W} / \mathrm{F}=0.5 \mathrm{~g} \cdot \mathrm{min} / \mathrm{ml}$, at $598 \mathrm{~K}$ and $27.5 \mathrm{bar}$. 


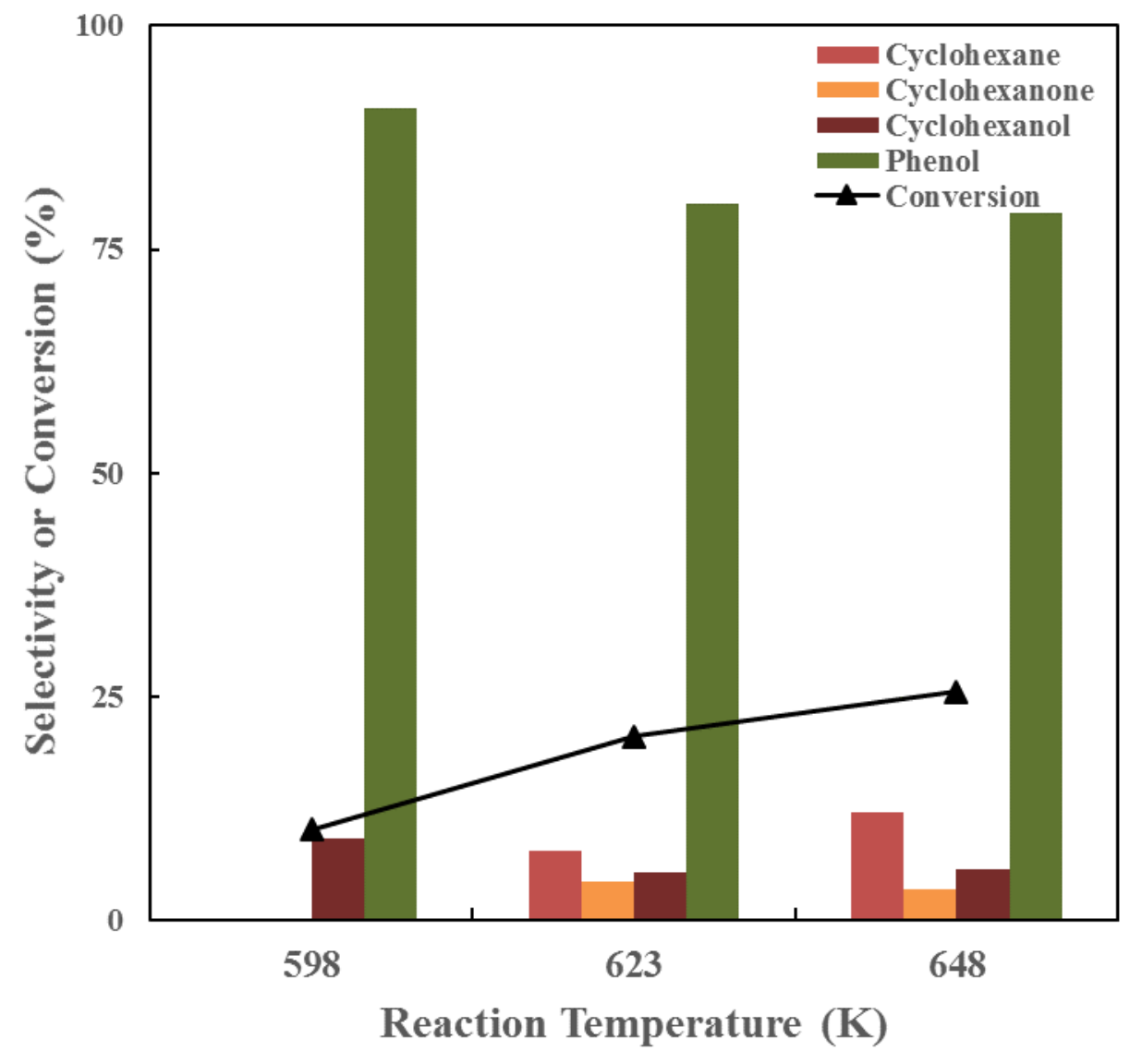

Figure 7. Product distribution for reaction of anisole on $\mathrm{PtZn}_{3} / \mathrm{C}$ catalyst as a function of temperature. $\mathrm{W} / \mathrm{F}=0.5 \mathrm{~g} * \mathrm{~min} / \mathrm{ml}, 27.5 \mathrm{bar}$ 
Table 1. Vibrational mode assignments.

\begin{tabular}{|c|c|c|c|}
\hline \multirow[b]{2}{*}{ Mode } & \multicolumn{3}{|l|}{ Frequency $\left(\mathrm{cm}^{-1}\right)$} \\
\hline & IR/Raman[33-35] & Pt (111) & $\mathrm{Zn} / \mathbf{P t}(111)$ \\
\hline$\gamma(\mathrm{C}-\mathrm{C})_{\text {ring }}$ (out of plane mode) & 509,513 & 500 & 500 \\
\hline Ring breathing & 785 & 780 & 780 \\
\hline$\gamma(\mathrm{C}-\mathrm{H})_{\text {ring }}$ (out of plane mode $)$ & 823,859 & 820 & - \\
\hline$\gamma(\mathrm{C}-\mathrm{H})_{\text {ring }}($ out of plane mode $)$ & 878,894 & 880 & - \\
\hline$\delta(C-H)_{\text {ring }}($ in plane mode $)$ & $1022,1029,997$ & 1010 & 1000 \\
\hline$v(\mathrm{O}-\mathrm{Me})+\mathrm{b}(\mathrm{C}-\mathrm{H})_{\text {ring }}($ out of plane mode $)$ & 1182,1183 & 1150 & 1150 \\
\hline$v(\mathrm{C}-\mathrm{OMe})+v(\mathrm{C}-\mathrm{H})_{\text {ring }}($ in plane mode $)$ & $1247,1252,1253$ & 1250 & 1250 \\
\hline$\delta(C-C)_{\text {ring }}$ (in plane mode $)+\delta(C-H)_{\text {methyl }}$ & $1453,1436,1468,1422$ & 1430 & 1440 \\
\hline $\mathrm{v}(\mathrm{C}-\mathrm{C})_{\text {ring }}($ in plane mode $)$ & 1588,1513 & 1550 & 1560 \\
\hline$v(C-H)_{m e t h y l}$ & 2900 & 2870 & 2880 \\
\hline$v(C-H)_{\text {ring }}$ & 3004 & 3000 & 3000 \\
\hline $\mathbf{v}(\mathbf{O}-\mathbf{H})$ & - & - & 3500 \\
\hline $\mathbf{v}(\mathbf{Z n}-\mathbf{O})$ & - & - & 400 \\
\hline $\mathbf{v}(\mathbf{P t}-\mathrm{C})$ & - & 470 & 470 \\
\hline \multicolumn{4}{|c|}{$\mathrm{s}$ - symmetric, as - asymmetric, $\mathrm{b}$ - bend, $v$ - stretch, $\delta$ - deformation, $\rho$ - rock, $\gamma$ - wag, $\chi$ - scissor } \\
\hline
\end{tabular}




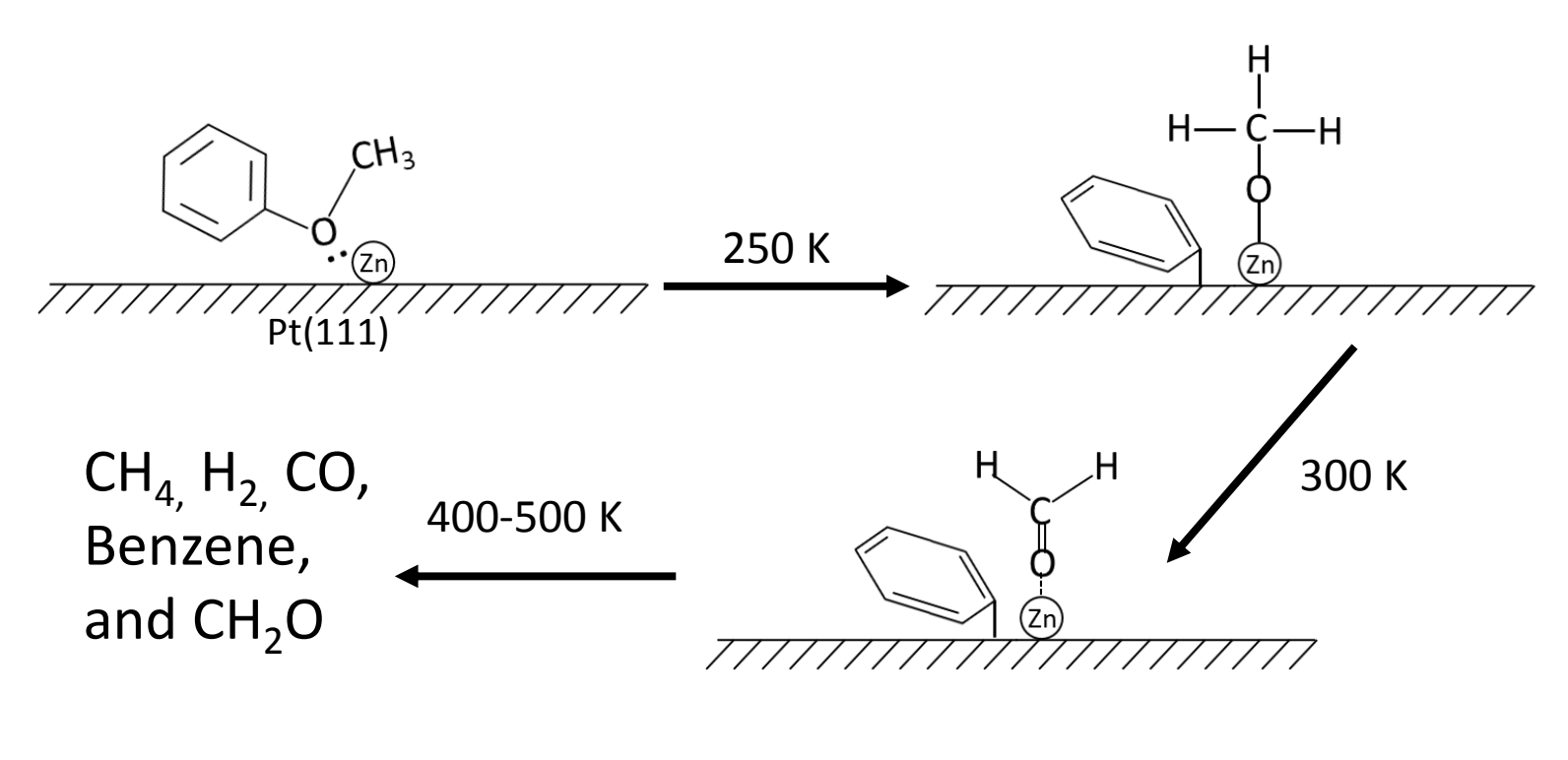

$\mathrm{CH}_{4}, \mathrm{H}_{2}, \mathrm{CO}_{2}$ and $\mathrm{CH}_{2} \mathrm{O}$

.

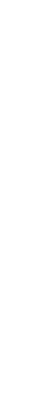

